\title{
Preparation of yttria-stabilized zirconia-ceria kernels as fuel precursors using internal gelation
}

\author{
By G. Benay, F. Hubert and G. Modolo* \\ Institut für Energieforschung (IEF-6), Forschungszentrum Jülich GmbH, 52425 Jülich, Germany
}

(Received June 15; accepted in revised form October 1, 2007)

\section{Internal gelation / Yttria-stabilized zirconia / Inert matrix fuel}

\begin{abstract}
Summary. Ceria-doped yttria-stabilized zirconia kernels were prepared by internal gelation and the effect that the concentration of HMTA and urea used in the initial broth had on the structure and properties of the gel was studied. Most combinations of urea and HMTA were found to provide gels with a smooth surface, which were assumed to be dense. However, a high quantity of urea and a low quantity of HMTA generated a gel with a rough surface, which was assumed to be porous and limited the formation of cracks during the thermal treatment of kernels. These kernels were then compacted using a repressing method whereby pellets with a sintered density up to $86 \%$ TD were formed. It was also found that the presence of urea is necessary to obtain good mechanical properties.
\end{abstract}

\section{Introduction}

Partitioning and transmutation (P\&T) and partitioning and conditioning $(\mathrm{P} \& \mathrm{C})$ are two promising methods for the management of spent nuclear fuel [1-3], both of which require suitable material for the loading of minor actinides retrieved from partitioning. Research into such a material focuses mainly on inert matrix mixed oxide fuels (IMMOX), among which yttria-stabilized zirconia is especially promising [4]. In addition to the formation of a solid solution with trivalent and tetravalent actinides, other interesting properties of this matrix include a small neutron capture cross section, a high melting point, and a high radiation and chemical stability [5-7].

The sol-gel methods are particularly suitable for preparing such matrices: the processes allow the solid to be shaped at the gel stage, prevent the formation of dust, and are simple enough to be handled remotely. Internal gelation in particular is technically very simple (on a laboratory scale) [8], which is why we chose to use it in our study. This process produces small beads or kernels, which can be directly used as fuel after sintering (SPHEREPAC process [9]). Alternatively, these kernels can be compacted into pellets [10].

Very few studies have focused on the internal gelation of yttria-stabilized zirconia $[8,11,12]$. However, the main

\footnotetext{
*Author for correspondence (E-mail: g.modolo@fz-juelich.de).
}

problem in the existing literature appears to be the formation of cracks during the thermal treatment of kernels. It is assumed that the quantities of hexamethylenetetramine (HMTA) and urea present in the initial broth have a significant influence on the properties and structure of the material. It should therefore be possible to optimize these properties by carefully choosing the composition.

In the present study, we focus on the preparation of gels of ceria-doped yttria-stabilized zirconia (cerium being a surrogate for trivalent actinides such as americium and/or curium in solution) in order to determine the HMTA and urea quantities that create the most interesting properties and structures, and on the application of these compositions in the synthesis of kernels and pellets. Their characterization by thermal analysis, electron microscopy and X-ray diffraction was also performed.

\section{Experimental}

\subsection{Synthesis of kernels and pellets}

$\mathrm{ZrOCl}_{2} \cdot 8 \mathrm{H}_{2} \mathrm{O}, \mathrm{Y}\left(\mathrm{NO}_{3}\right)_{3} \cdot 6 \mathrm{H}_{2} \mathrm{O}$ and $\mathrm{Ce}\left(\mathrm{NO}_{3}\right)_{3} \cdot 6 \mathrm{H}_{2} \mathrm{O}$ salts with a purity of $99.9 \%$ (Alfa Aesar) were dissolved in deionised water at room temperature to reach a final metal concentration of $1.6 \mathrm{~mol} / \mathrm{L}$ and a molar composition of $76 \% \mathrm{Zr}, 14 \% \mathrm{Y}$ and $10 \% \mathrm{Ce}$. A second solution was prepared by dissolving varying concentrations of urea (Merck, p.a.) and hexamethylentetramine HMTA (Merck, synthesis grade) in deionised water. The two solutions were then mixed at $3{ }^{\circ} \mathrm{C}$. The final solution, or broth, contained concentrations of urea between 0.0 and $1.6 \mathrm{~mol} / \mathrm{L}$, and concentrations of HMTA between 0.24 and $0.56 \mathrm{~mol} / \mathrm{L}$. Higher concentrations were found to cause difficulties, such as premature gelation, as was observed for [HMTA] $>0.6 \mathrm{~mol} / \mathrm{L}$. The relative molar concentrations of urea and HMTA to the total metal concentration are defined by the two molar ratios $R_{\mathrm{U}}=$ [urea] $/\left[\right.$ metal] $(\mathrm{mol} / \mathrm{mol})$ and $R_{\mathrm{H}}=$ [HMTA] $/[$ metal] $(\mathrm{mol} / \mathrm{mol})$, where metal is the sum of metallic cations. The broth was then placed in the syringe of a syringe pump and dropped through a $0.4 \mathrm{~mm}$ diameter nozzle with a flow rate of $40 \mathrm{~mL} / \mathrm{h}$ into a thermostated bath of silicone oil kept at a constant temperature of $c a .90^{\circ} \mathrm{C}$. The heat caused HMTA to decompose into formaldehyde and ammonia according to Eqs. (1) and (2) [13]: 


$$
\begin{gathered}
\left(\mathrm{CH}_{2}\right)_{6} \mathrm{~N}_{4}+\mathrm{H}^{+} \rightleftharpoons\left[\left(\mathrm{CH}_{2}\right)_{6} \mathrm{~N}_{4} \mathrm{H}\right]^{+} \\
{\left[\left(\mathrm{CH}_{2}\right)_{6} \mathrm{~N}_{4} \mathrm{H}\right]^{+}+3 \mathrm{H}^{+}+4 \mathrm{NO}_{3}{ }^{-} \rightarrow} \\
4 \mathrm{NH}_{4}{ }^{+}+4 \mathrm{NO}_{3}{ }^{-}+6 \mathrm{CH}_{2} \mathrm{O} .
\end{gathered}
$$

Then, the ammonia induced the precipitation of the metal hydroxides (Eq. (3), e.g. formation of zirconium hydroxide) into gel spheres:

$$
\begin{gathered}
{\left[\mathrm{Zr}_{4}(\mathrm{OH})_{8}\left(\mathrm{OH}_{2}\right)_{16}\right]^{8+}+8 \mathrm{H}_{2} \mathrm{O} \rightarrow} \\
{\left[\mathrm{Zr}_{4}(\mathrm{OH})_{16} \cdot 16 \mathrm{H}_{2} \mathrm{O}\right]+8 \mathrm{H}^{+} .}
\end{gathered}
$$

After an aging phase of half an hour in oil, the kernels were separated on a Büchner system and washed with carbon tetrachloride to remove silicone oil. They were subsequently rinsed with a $2 \mathrm{~mol} / \mathrm{L}$ ammonia solution to remove by-products, such as ammonium nitrate and chloride. The efficiency of this washing step was controlled by conductivity measurements and ICP-MS of the effluent. The kernels were rinsed with distilled water until the $\mathrm{pH}$ of the solution became neutral. At the end of the washing step, the kernels had a yellow colour, which is characteristic of $\mathrm{Ce}(\mathrm{IV})$. After washing, the kernels were dried in air overnight at room temperature and then placed in an oven at $110^{\circ} \mathrm{C}$. Finally, they were calcined in air at $600^{\circ} \mathrm{C}$ for $2 \mathrm{~h}$.

Some of the kernels (approximately $0.5 \mathrm{~g}$ of them per batch) were compacted into cylindrical pellets with a diameter of $10 \mathrm{~mm}$ either by cold uniaxial pressing or by repressing. Zinc stearate dissolved in diethyl ether was used as a lubricant. The pressure applied was of $900 \mathrm{MPa}$. In the case of repressing, the kernels were first compacted, then granulated and recompacted. Finally, the pellets were sintered at $1600{ }^{\circ} \mathrm{C}$ for $5 \mathrm{~h}$ in air atmosphere.

\subsection{Characterization}

The gelation temperatures of broths (mixture of urea, HTMA and metal salt) were determined by viscosimetric measurements in order to define an area of feasibility and observe whether HMTA and urea promote or inhibit the gelation. The broth was poured into the viscosimeter chamber (HAAKE Viscotester 550 rotational viscosimeter) and placed in a thermostated water bath where it was heated from room temperature with a heating rate of $6^{\circ} \mathrm{C} / \mathrm{min}$ until it massively gelled (or up to $90^{\circ} \mathrm{C}$ if no gelation occurred). During this process, the temperature was continuously recorded. The gelation temperature corresponds to the temperature of a steep increase in viscosity (from around $50 \mathrm{mPa}$ s to over $500 \mathrm{mPas}$ ). The gel was then dried in air at room temperature and finally heated to a temperature of $110^{\circ} \mathrm{C}$.

The characteristics of the morphological structures were investigated using an optical microscope and scanning electron microscope (JEOL JSM-840) coupled with an energy dispersive X-ray analyser (EDX). The surfaces of the observed sections of pellets were first mechanically polished with abrasive paper and subsequently finished using diamond paste buffing. The kernels and gels were observed without specific treatment with the exception of gold coating.

The thermal behaviour of the kernels during heating in air from room temperature to $1300{ }^{\circ} \mathrm{C}$ was investigated by thermogravimetry (TG) and differential scanning calorimetry (DSC). They were heated in air with a heating rate of $10^{\circ} \mathrm{C} / \mathrm{min}$ (Netzsch STA 449C Jupiter apparatus).

The crystal structure of the kernels was investigated by $\mathrm{X}$-ray diffraction at room temperature (Stoe TransmissionsDiffractometer-System STADI, Co $K_{\alpha}, \lambda=0.178897 \mathrm{~nm}$ ). The lattice parameter was determined using the NelsonRiley method [14]. The relative degree of crystallinity $(G$, in \%) after treatment at a temperature $T$ was calculated for all kernels using the following formula [15]:

$$
G=100\left(I / I_{0}\right) /\left(I_{\mathrm{S}} / I_{0 \mathrm{~S}}\right),
$$

where $I$ represents the intensity of the (111) peak of the kernels studied and $I_{0}$ its background signal at the temperature $T . I_{\mathrm{S}}$ and $I_{0 \mathrm{~S}}$ correspond to the intensity of the (111) peak and the background signal of the same kernels after treatment at $1300{ }^{\circ} \mathrm{C}$, the temperature at which they are considered to be a totally crystalline material.

The green densities $\left(\rho_{\mathrm{G}}\right)$, or densities before sintering of the pressed pellets were determined using the geometrical method and the sintered densities $\left(\rho_{\mathrm{S}}\right)$ of the pellets were determined by hydrostatic weighing in water.

\section{Results and discussion}

\subsection{Gelation process}

Gelation temperatures were measured by viscosimetry for solutions prepared with $76 \mathrm{~mol} \% \mathrm{Zr}, 14 \mathrm{~mol} \% \mathrm{Y}$ and $10 \mathrm{~mol} \% \mathrm{Ce}$, and different urea/metal $\left(R_{\mathrm{U}}\right)$ and HTMA/ metal $\left(R_{\mathrm{H}}\right)$ ratios. The results for $R_{\mathrm{U}}$ between 0.0 and 2.0 and $R_{\mathrm{H}}$ between 0.3 and 0.6 are summarised in Fig. 1. The gelation temperature varies between $87^{\circ} \mathrm{C}$ and $55^{\circ} \mathrm{C}$. It

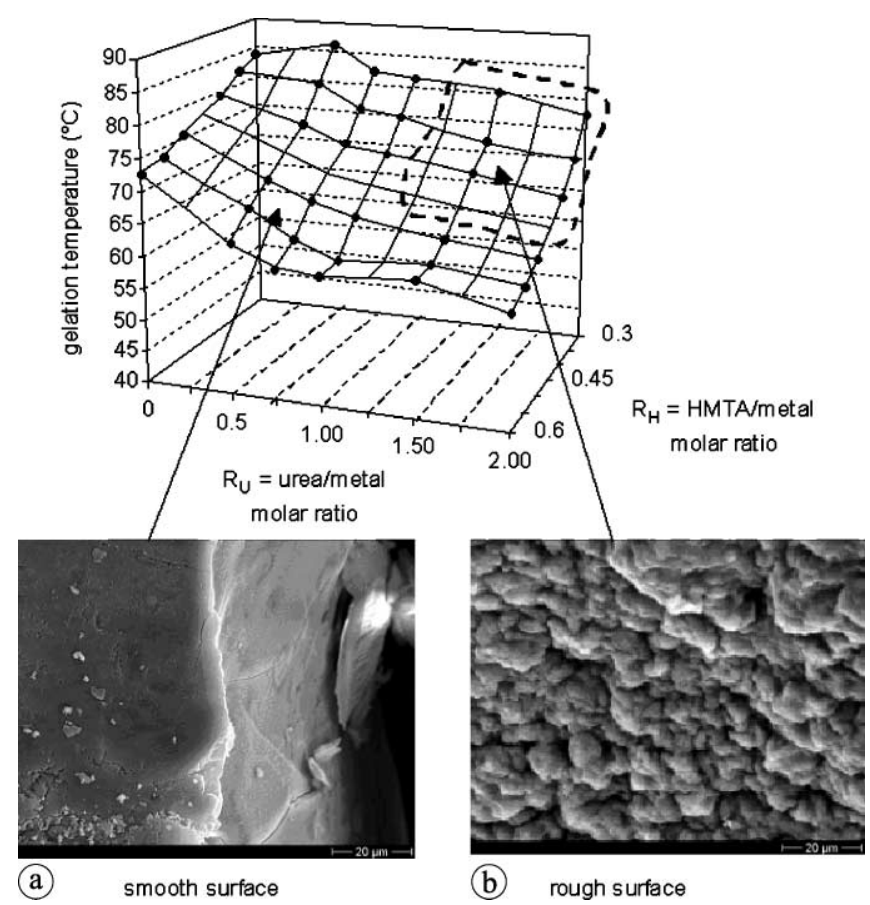

Fig. 1. Gelation temperatures for different broth compositions and the structures of resulting gels with $76 \mathrm{~mol} \% \mathrm{Zr}, 14 \mathrm{~mol} \% \mathrm{Y}$ and $10 \mathrm{~mol} \% \mathrm{Ce}$ in initial broth. 
was observed that for any constant $R_{\mathrm{U}}$, this temperature decreases when $R_{\mathrm{H}}$ increases from 0.3 to 0.6 . This indicates that more HMTA in the broth favours hydroxide precipitation, allowing gel formation to occur at lower temperatures. On the other hand, the gelation temperature also decreases when $R_{\mathrm{U}}$ increases for a constant value of $R_{\mathrm{H}}$. This can be explained by a catalytic effect of urea on the decomposition of HMTA, as observed by Collins et al. [13]. In their paper, they attribute this either to a reaction between formaldehyde (from HMTA decomposition) and urea, which forms monomethylol urea, and thus shifts the equilibrium of Eq. (2) towards HMTA decomposition, or a chemical reaction between urea and HMTA.

The structure of gels dried at $110^{\circ} \mathrm{C}$ was studied by SEM. A rough surface was observed for $R_{\mathrm{U}}$ between 1.5 and 2.0 and $R_{\mathrm{H}}$ between 0.3 and 0.4 (see right picture in Fig. 1), whereas a smooth surface was observed otherwise (see left picture in Fig. 1). The rough surface, which is supposedly linked to a porous structure, corresponds to a high quantity of urea, which generates a sustained mesoporous character of the material upon decomposition [16], and a low quantity of HMTA, which limits the density of the gel due to a less favorable gelation. Both factors appeared necessary to create this specific structure.

\subsection{Fabrication and characterization of kernels}

Kernels containing $76 \mathrm{~mol} \% \mathrm{Zr}, 14 \mathrm{~mol} \% \mathrm{Y}$ and $10 \mathrm{~mol} \%$ Ce were prepared with broth compositions corresponding to the rough and smooth surface domains observed for the gels (see Table 1). The sample with no urea $\left(R_{\mathrm{U}}=0.0\right.$ and $R_{\mathrm{H}}=$ 0.6 , sample 1) was used as reference. Samples 2 to 4 belong
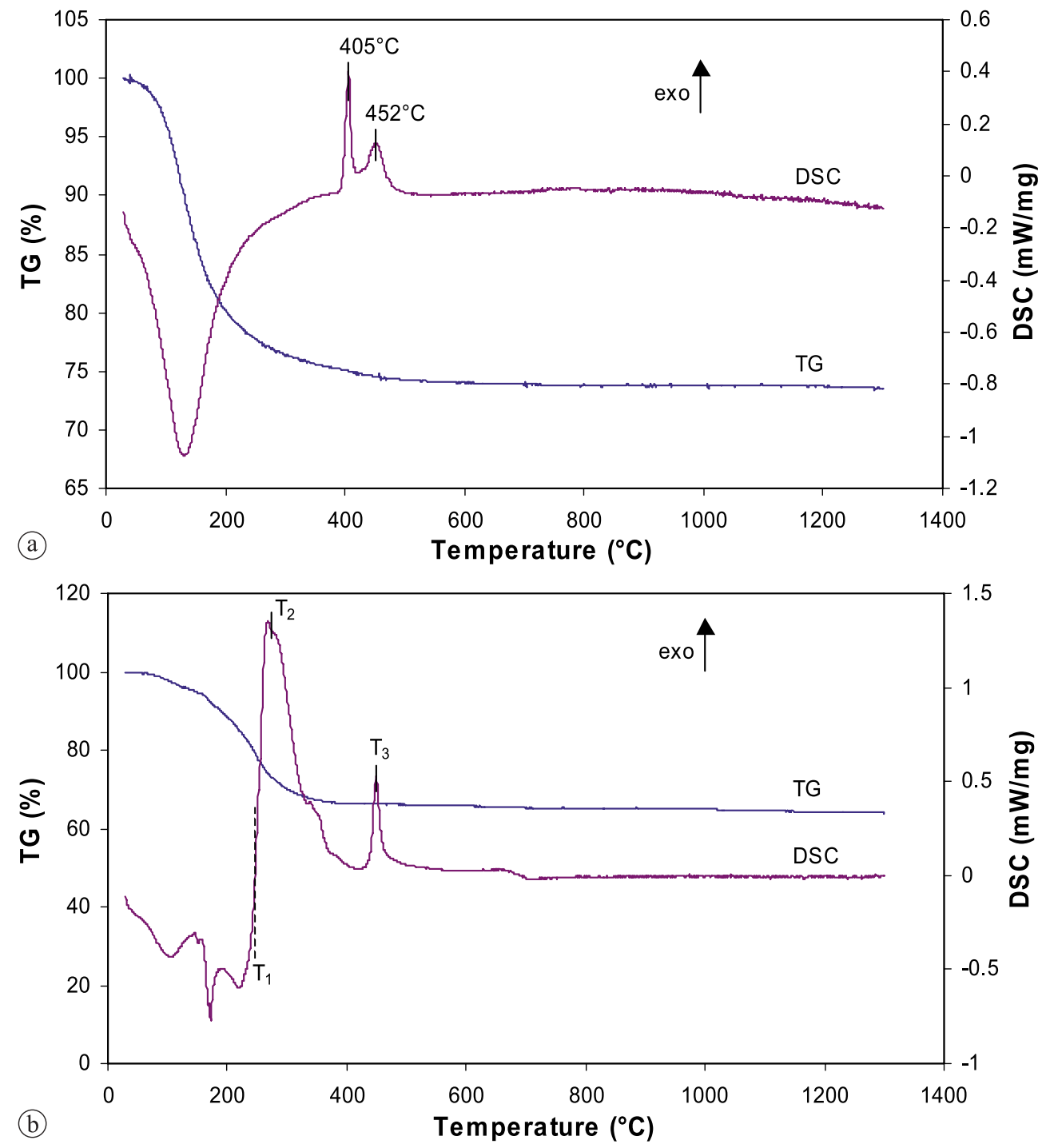

Fig. 2. Thermal analysis of kernels with $76 \mathrm{~mol} \% \mathrm{Zr}, 14 \mathrm{~mol} \%$ $\mathrm{Y}$ and $10 \mathrm{~mol} \% \mathrm{Ce}$ in initial broth - (a) $R_{\mathrm{U}}=0.0, R_{\mathrm{H}}=0.6-(\mathbf{b})$ $R_{\mathrm{U}}=1.5, R_{\mathrm{H}}=0.3$.

Table 1. Composition of initial broth solutions used for the preparation of kernels.

\begin{tabular}{lcccccccc}
\hline Sample number & 1 & 2 & 3 & 4 & 5 & 6 & 7 & 8 \\
\hline$R_{\mathrm{U}}$ (urea/metal) & 0.00 & 0.50 & 0.75 & 1.00 & 1.50 & 1.50 & 2.00 & 2.00 \\
$R_{\mathrm{H}}$ (HMTA/metal) & 0.60 & 0.60 & 0.56 & 0.56 & 0.30 & 0.40 & 0.30 & 0.40 \\
\hline
\end{tabular}


Table 2. Results of thermal analysis for the different kernels studied with $76 \mathrm{~mol} \% \mathrm{Zr}, 14 \mathrm{~mol} \% \mathrm{Y}$ and $10 \mathrm{~mol} \% \mathrm{Ce}$ in initial broth.

\begin{tabular}{lllccccrcr}
\hline $\begin{array}{l}\text { Sample } \\
\text { number }{ }^{a}\end{array}$ & $R_{\mathrm{U}}$ & $R_{\mathrm{H}}$ & $\begin{array}{c}\text { Total mass } \\
\text { loss }(\%)\end{array}$ & $\begin{array}{c}T_{1} \\
\left({ }^{\circ} \mathrm{C}\right)\end{array}$ & $\begin{array}{c}T_{2} \\
\left({ }^{\circ} \mathrm{C}\right)\end{array}$ & $\begin{array}{c}T_{3} \\
\left({ }^{\circ} \mathrm{C}\right)\end{array}$ & $\begin{array}{c}Q_{1}^{b} \\
(\mathrm{~J} / \mathrm{g})\end{array}$ & $\begin{array}{c}Q_{2}^{c} \\
(\mathrm{~J} / \mathrm{g})\end{array}$ & $\begin{array}{c}\text { Mass loss from } \\
R T \text { to } T_{1}(\%)\end{array}$ \\
\hline 2 & 0.5 & 0.6 & 33.7 & 248 & 276 & 434 & 346 & 59 & 23.4 \\
3 & 0.75 & 0.56 & 43.0 & 251 & 279 & 453 & 988 & 33 & 26.9 \\
4 & 1.0 & 0.56 & 45.3 & 257 & 311 & 473 & 1408 & 11 & 25.8 \\
5 & 1.5 & 0.3 & 33.7 & 247 & 268 & 449 & 511 & 47 & 20.9 \\
6 & 1.5 & 0.4 & 37.0 & 249 & 288 & 466 & 986 & 46 & 21.7 \\
7 & 2.0 & 0.3 & 30.7 & 236 & 281 & 458 & 502 & 62 & 18.7 \\
8 & 2.0 & 0.4 & 37.8 & 247 & 286 & 460 & 921 & 54 & 21.3 \\
\hline
\end{tabular}

a: samples numbered according to Table 1;

b: specific heat of the first exothermic effect;

c: specific heat of the second exothermic effect.

to the smooth surface domain and samples 5 to 8 to the rough surface domain.

All of these kernels were analysed by TG-DSC. Without urea (Fig. 2a), an endothermic effect associated with a mass loss of $24.7 \%$ from $25^{\circ} \mathrm{C}$ to $350{ }^{\circ} \mathrm{C}$ was observed. Two exothermic peaks were then observed at $405^{\circ} \mathrm{C}$ and $452{ }^{\circ} \mathrm{C}$ with respective specific heats of $24 \mathrm{~J} / \mathrm{g}$ and $22 \mathrm{~J} / \mathrm{g}$. The thermal behaviour when urea was present was different and all studied compositions containing urea exhibited a similar behaviour (see Fig. $2 b$ as a representative example and Table 2 for detailed data). A significant mass loss was first observed with a temperature increase from $25^{\circ} \mathrm{C}$ to $400^{\circ} \mathrm{C}$. This was associated with endothermic effects from $25^{\circ} \mathrm{C}$ to temperature $T_{1}$, followed by a strong exothermic effect with a maximum at temperature $T_{2}$. A smaller exothermic effect was subsequently observed at temperature $T_{3}$.

In order to explain these results, the thermal decomposition of HMTA and urea was studied (Fig. 3). HMTA alone showed an endothermic peak at $206^{\circ} \mathrm{C}$ corresponding to sublimation and decomposition [17]. On the other hand, urea showed four endothermic peaks corresponding to the melting of urea at $135^{\circ} \mathrm{C}$, the decomposition of urea into cyanic acid, $\mathrm{HNCO}$, and ammonia, and the production of biuret $\mathrm{NH}\left(\mathrm{CONH}_{2}\right)_{2}$ at $182{ }^{\circ} \mathrm{C}$. The decomposition of biuret and the production of cyanuric acid $(\mathrm{CONH})_{3}$, cyanic acid and ammonia at $226^{\circ} \mathrm{C}$, and the decomposition of cyanuric acid at $314^{\circ} \mathrm{C}$ were then observed (only the main decomposition products are cited) [18]. A mixture of HMTA and urea (Fig. 3c) showed endothermic peaks at $124^{\circ} \mathrm{C}, 172^{\circ} \mathrm{C}$ and $253^{\circ} \mathrm{C}$, which can be related to the melting of urea and the decomposition stages. A large exothermic peak was then observed at $352{ }^{\circ} \mathrm{C}$ corresponding to reactions between the decomposition products of HMTA and urea.

Previous studies on ceria containing yttria-stabilized zirconia prepared by coprecipitation [19] have shown that crystallization of the material in a face-centered cubic $(f c c)$ fluorite structure occurs between $300{ }^{\circ} \mathrm{C}$ and $600{ }^{\circ} \mathrm{C}$ with an exothermic effect. We can therefore conclude that the first endothermic mass loss corresponds to the elimination of residual water, and that the smaller exothermic effects at $452{ }^{\circ} \mathrm{C}$ without urea and at $T_{3}$ with urea ( $c f$. Fig. 2) are linked to the crystallization of the material. The strong exothermic effect observed between $250{ }^{\circ} \mathrm{C}$ and $400{ }^{\circ} \mathrm{C}$ when urea was present (whose maximum is noted as $T_{2}$ in Fig. 2) would then correspond to the elimination of the residual decom-
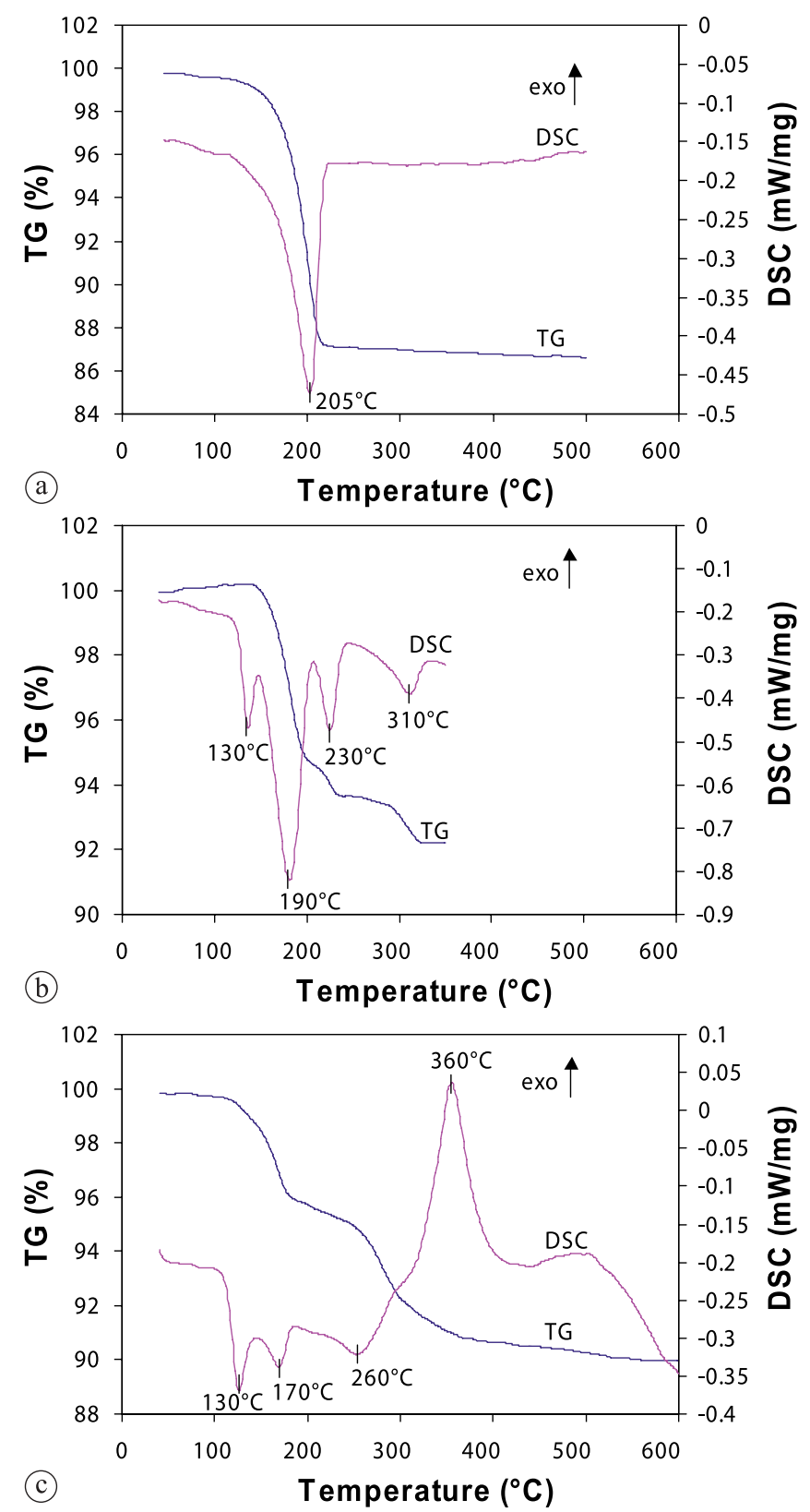

Fig. 3. Thermal analysis of HMTA (a), urea (b) and a $1: 1(w / w)$ mixture of HMTA and urea (c) diluted in aluminium oxide.

position products of HMTA and urea. It could additionally be due to the elimination of residual ammonia [20,21]. The exothermic effect observed at $405^{\circ} \mathrm{C}$ without urea could be 


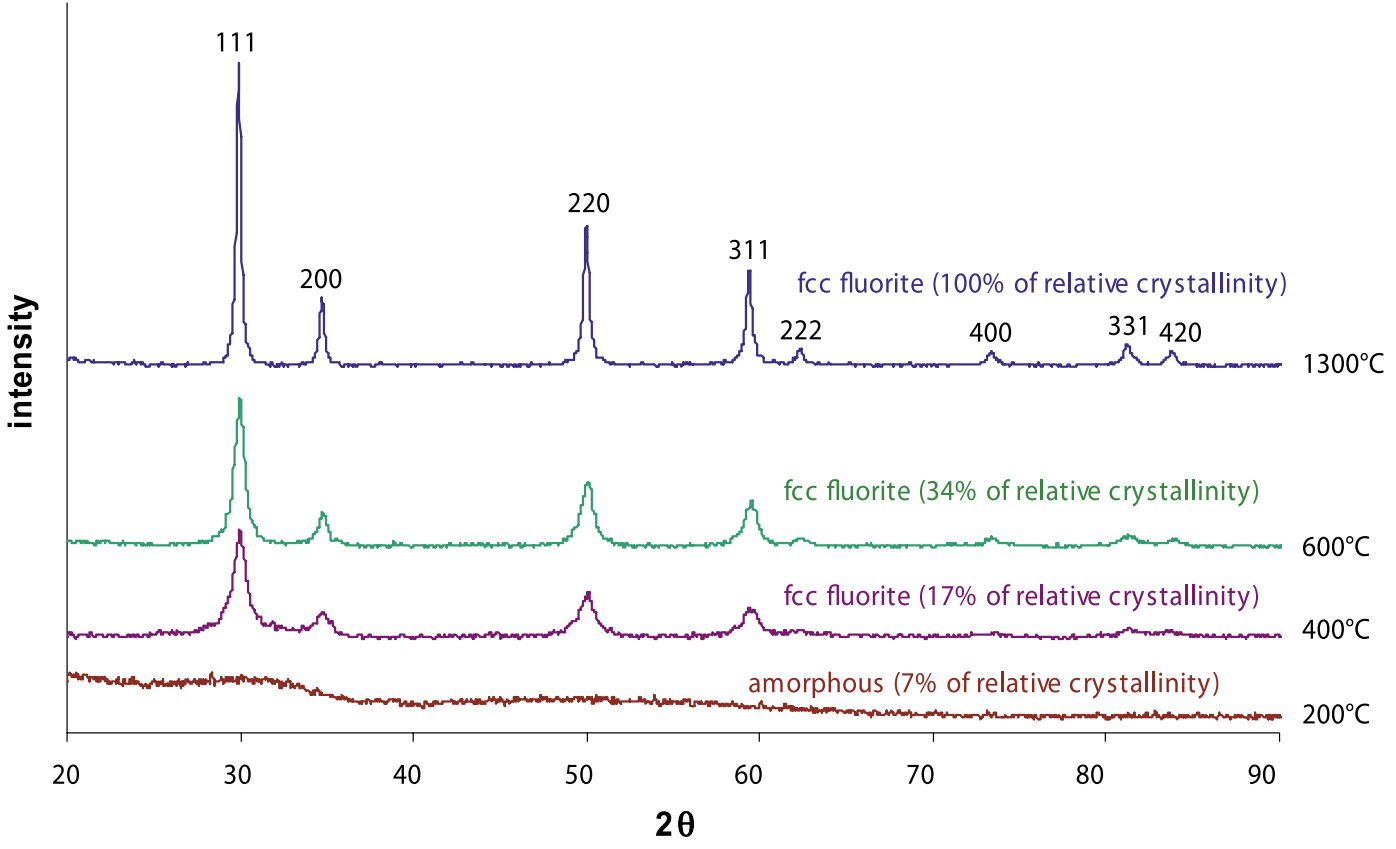

Fig. 4. XRD patterns of $\mathrm{Zr}_{0.76} \mathrm{Y}_{0.14} \mathrm{Ce}_{0.10} \mathrm{O}_{2-x}$ kernels with $R_{\mathrm{U}}=2.0$ and $R_{\mathrm{H}}=0.3$ after calcination at different temperatures (measurements performed at room temperature). due to the decomposition of silicone oil, which remained on the surface of the kernels, in some of the samples.

As can be seen in Fig. 4, XRD patterns show that kernels with $76 \mathrm{~mol} \% \mathrm{Zr}, 14 \mathrm{~mol} \% \mathrm{Y}$ and $10 \mathrm{~mol} \% \mathrm{Ce}$ are amorphous up to $200^{\circ} \mathrm{C}$. The material starts to crystallise in an fcc fluorite structure at $400{ }^{\circ} \mathrm{C}$. This behaviour was found to be the same for all broth compositions studied. It corresponds to the formation of a solid solution of $\mathrm{Zr}_{0.76} \mathrm{Y}_{0.14} \mathrm{Ce}_{0.10} \mathrm{O}_{2-x}$. The crystallinity rates as a function of temperature were also calculated and found to be similar for all compositions studied. The material can be considered amorphous up to $200^{\circ} \mathrm{C}$ with a relative crystallinity of $7 \%$. Crystallization had already begun at $400{ }^{\circ} \mathrm{C}$ and was quite high at $600{ }^{\circ} \mathrm{C}(34 \%)$ compared to powder of the same material obtained by the co-precipitation of hydroxides (only $20 \%$ crystallinity) [22]. These results show that premature crystallization occurred as a result of the heat released during the elimination of impurities between $250{ }^{\circ} \mathrm{C}$ and $400{ }^{\circ} \mathrm{C}$. Therefore, the second exothermic peak observed around $450^{\circ} \mathrm{C}$ corresponds to a phase transition prior to recrystallization.

Figure 5 shows that a progressive stabilisation of the lattice parameter occurs as the temperature and crystallinity of the material increases. The relatively low value of the lattice parameter at $1300{ }^{\circ} \mathrm{C}(5.1567 \pm 0.0032 \AA)$ compared to what would have been expected from Vegard's law (5.1685 $\AA$ ) could be attributed to some losses during fabrication. Indeed, a measurement of the composition of the effluents by ICP-MS indicated that around $2.5 \%$ of the cerium and yttrium present was not fixed into the kernels. In comparison, only $0.3 \%$ zirconium losses were observed.

The structure of the kernels observed by SEM was similar to the gel structures (see pictures in Fig. 1): a smooth surface for $R_{\mathrm{U}}$ less than 1.0 or $R_{\mathrm{H}}$ greater than 0.5 and a rough surface for $R_{\mathrm{U}}$ greater than 1.5 and $R_{\mathrm{H}}$ less than 0.4 . No cracks were observed on kernels with a rough surface after drying at $110^{\circ} \mathrm{C}$. On the contrary, kernels with a smooth surface exhibited cracks at this temperature. It can be concluded that a porous structure, which can be associ-

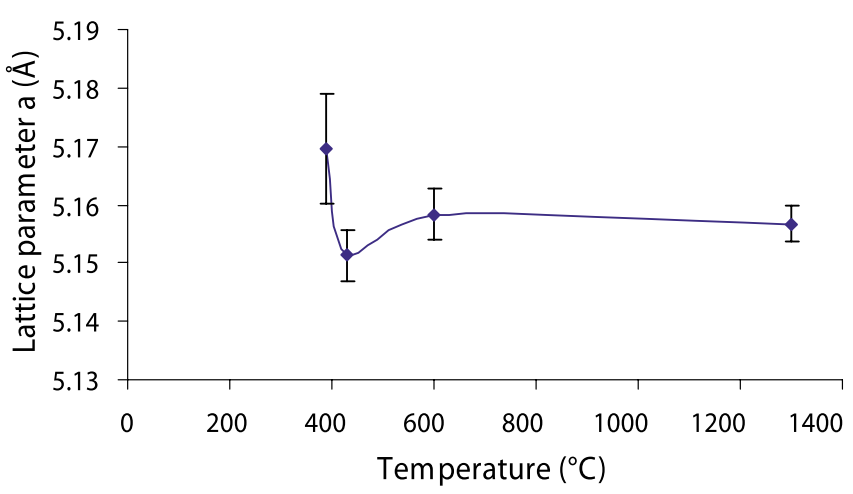

Fig. 5. Evolution of the lattice parameter of $\mathrm{Zr}_{0.76} \mathrm{Y}_{0.14} \mathrm{Ce}_{0.10} \mathrm{O}_{2-x}$ kernels with $R_{\mathrm{U}}=2.0$ and $R_{\mathrm{H}}=0.3$ with temperature.

ated with a rough surface, allows the gases produced during the first part of the thermal treatment to be released with less difficulty. However, even when the rough kernels were slowly $\left(0.5^{\circ} \mathrm{C} / \mathrm{min}\right.$ on average) heated to $600{ }^{\circ} \mathrm{C}$, cracks were formed. This is probably due to the fact that the theoretically porous structure was not sufficient to resist the exothermic elimination of impurities and the overpressure caused by the gaseous by-products of this elimination. More care is therefore required during the different preparation steps in order to obtain a suitable material. It should also be noted that the kernels without urea were severely broken after thermal treatment, which indicates that urea is necessary if better mechanical properties of the material are to be obtained.

\subsection{Fabrication and characterization of pellets}

Calcined kernels of $\mathrm{Zr}_{0.76} \mathrm{Y}_{0.14} \mathrm{Ce}_{0.10} \mathrm{O}_{2-x}$ were pressed into pellets as they are a convenient shape and have the added advantage that cracked kernels can be used. It is also compatible with the requirements of a dust-free remotely handled process, in contrast to powder milling and pressing which are currently used for fuel fabrication. However, dir- 


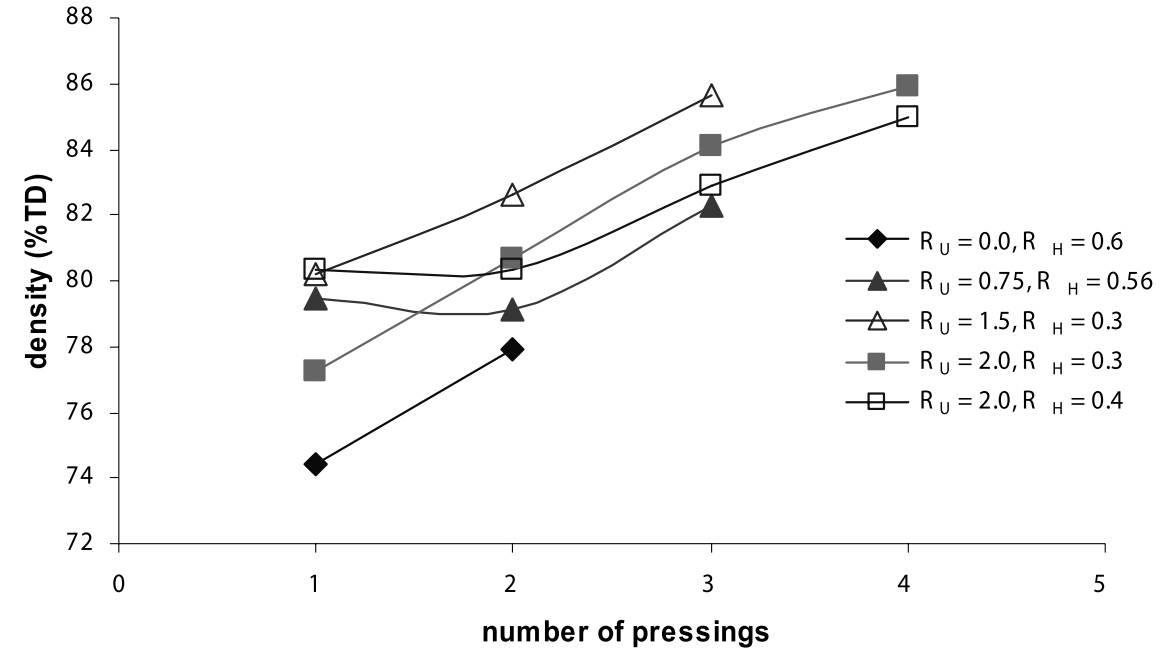

Fig. 6. Sintered densities of selected pellets of $\mathrm{Zr}_{0.76} \mathrm{Y}_{0.14} \mathrm{Ce}_{0.10} \mathrm{O}_{2-x}$ prepared with different initial broth compositions and number of pressings.

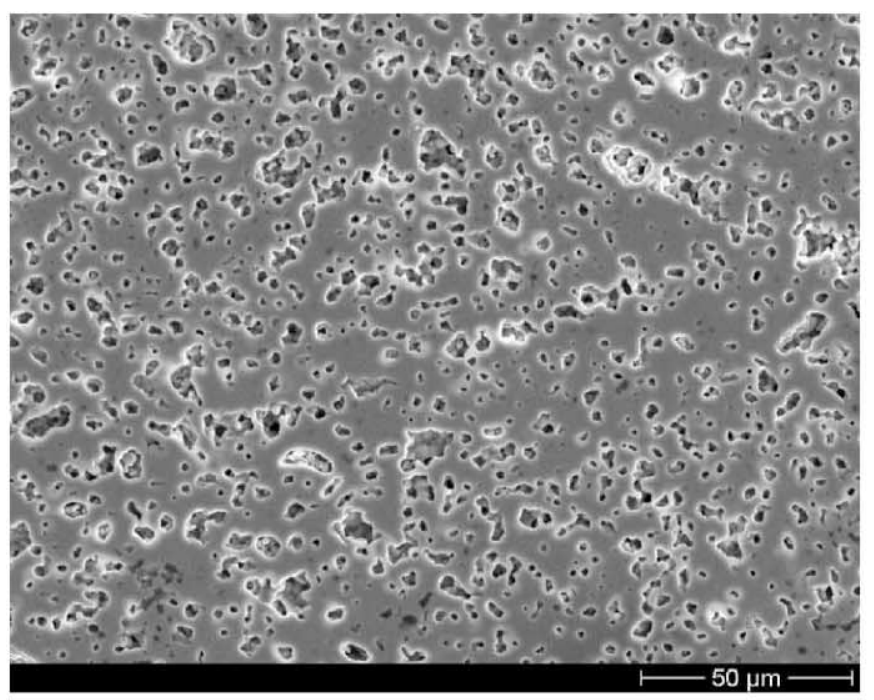

(a)

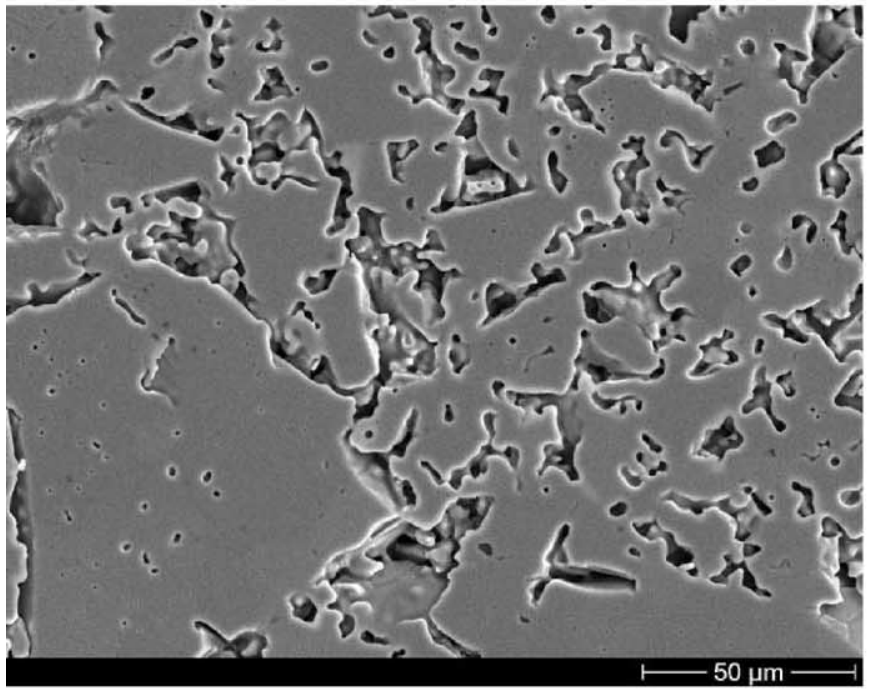

(c)

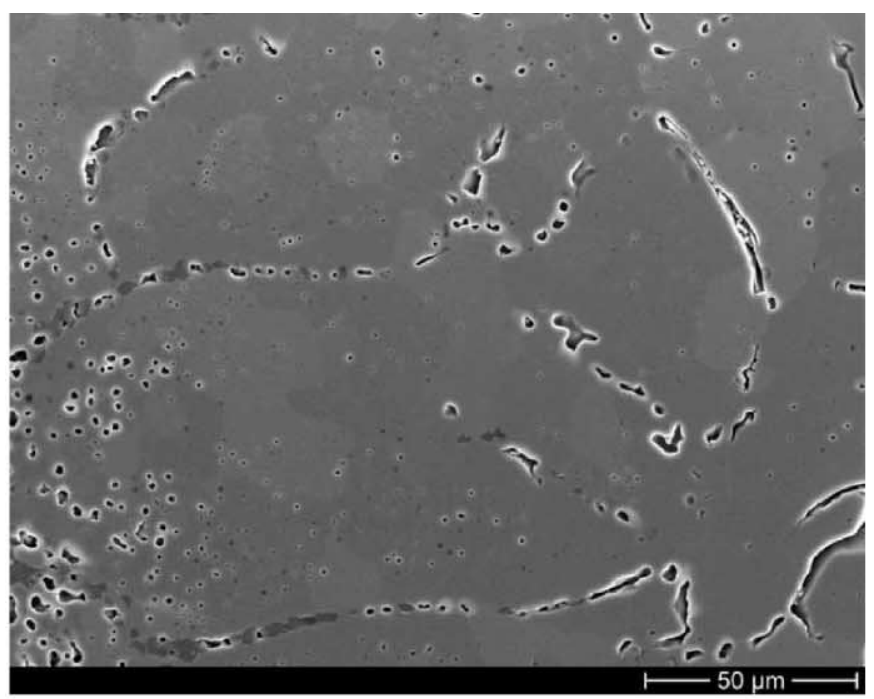

(b)

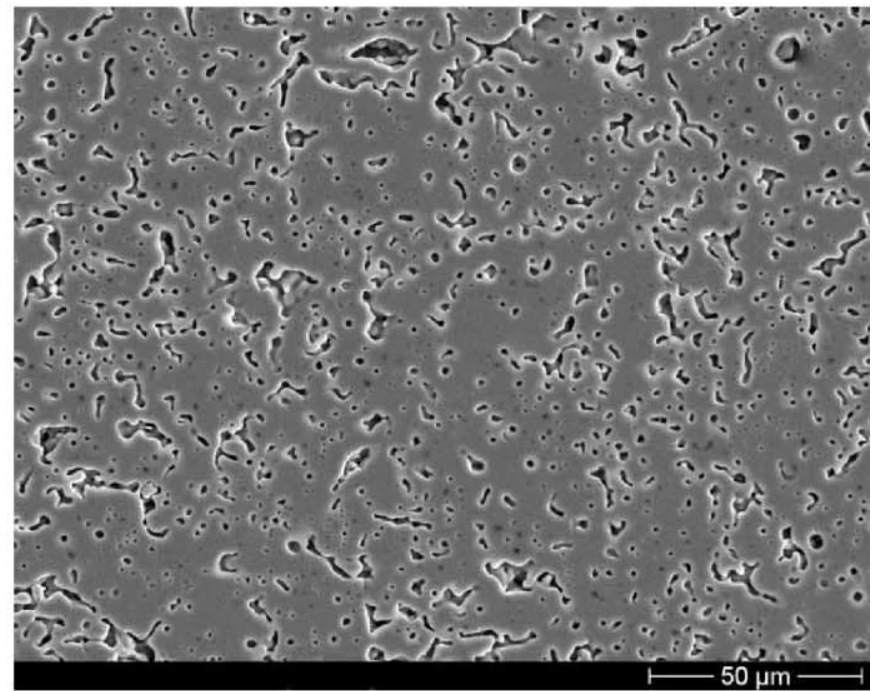

(d)

Fig. 7. $\mathrm{SEM}$ pictures of sintered $\mathrm{Zr}_{0.76} \mathrm{Y}_{0.14} \mathrm{Ce}_{0.10} \mathrm{O}_{2-x}$ pellets; (a) $R_{\mathrm{U}}=0.0, R_{\mathrm{H}}=0.6$, single pressing; (b) $R_{\mathrm{U}}=0.5, R_{\mathrm{H}}=0.6$, single pressing; (c) $R_{\mathrm{U}}=0.5, R_{\mathrm{H}}=0.6$, repressed once; (d) $R_{\mathrm{U}}=2.0, R_{\mathrm{H}}=0.4$, repressed twice.

ect pressing of the kernels does not completely break them and their original shape is recognisable in the pellets. This effect is known as the "berry structure" and it limits the density of the material [23]. Repressing was therefore used to break the kernels and prevent this berry structure from forming. Figure 6 summarises the densities measured. It can 
be seen that increasing the number of repressing steps increases the sintered density in all cases, as expected. Up to $86 \%$ theoretical density can be achieved. It should also be noted that pellets prepared from broths containing no urea ( $R_{\mathrm{U}}=0$, full diamonds in Fig. 6) were less dense than the others.

The surfaces of all pellets were studied by SEM (Fig. 7). The kernels prepared without urea were broken during calcination, therefore no berry structure was observed on the pellets. They were however highly porous (Fig. 7a). This is due to the fact that kernels fragments act like hard agglomerates which cause bad sintering [24]. In the presence of urea, a berry structure can be clearly observed after a single pressing. The precise microstructure, especially inside the kernels depends on the structure of the corresponding gel. A gel structure with a low urea content and a relatively high quantity of HMTA was found to be extremely dense (Fig. 7b). In this case, kernels can be considered as hard agglomerates. Repressing allows the kernels to be broken, but hard agglomerates with poor sinterability remain (Fig. 7c). For high contents of urea and low quantities of HMTA (supposedly porous gel structure), the structure inside the kernels after a single pressing was also dense, but the porosity was slightly higher due to a lower green density. Repressing the pellets allowed the agglomerates to be progressively broken until a homogeneous structure was obtained (Fig. 7d). However, the density remained low with some porosity because the green density was too low. It would be interesting to use the composition in Fig. 7b (low urea and relatively high HMTA) for kernels, if crack formation could be prevented because of the extreme density observed inside the kernels.

\section{Summary}

In this study, the internal gelation process was used to fabricate zirconia-based inert material which is attractive as a matrix for the transmutation of actinides. Kernels containing $76 \mathrm{~mol} \% \mathrm{Zr}, 14 \mathrm{~mol} \% \mathrm{Y}$ and $10 \mathrm{~mol} \% \mathrm{Ce}$ were prepared and it was observed that both urea and HMTA play a major role in the structure and properties of materials obtained by internal gelation. An urea/metal ratio higher than 1.5 and an HMTA/metal ratio lower than 0.4 allow the formation of kernels with a rough surface, which resist cracking up to $110^{\circ} \mathrm{C}$. Other compositions provide a theoretically dense material, that cracked at $110^{\circ} \mathrm{C}$. Subsequent thermal treatment proved unsuccessful in preserving uncracked kernels, even with low heating rates. Strong exothermic effects appear to be caused by mixing urea with HMTA. More studies are therefore needed on maintaining uncracked kernels at temperatures above $110^{\circ} \mathrm{C}$ and ensuring complete gelation without material losses. As an alternative, the kernel pelletization process was studied as a dust-free method that can be remotely handled. It proved to be compatible with cracked kernels, and allowed the fabrication of pellets with densities up to $86 \%$ TD. The calcination and sintering conditions could however be improved to obtain even better densities.

Acknowledgment. This work was supported by the European Union (EUROPART, contract No. F16W-CT-2003-508854). The authors wish to thank W. Reichert for numerous XRD measurements.

\section{References}

1. Actinide and fission product partitioning and transmutation - Status and assessment report, OECD-NEA (1999).

2. Accelerator driven systems (ADS) and fast reactors (FR) in advanced fuel cycles - A comparative study, OECD-NEA (2002).

3. Implications of partitioning and transmutation in radioactive waste management. Vienna, International Atomic Energy Agency, Technical Reports Series, ISSN 0074-1914, No. 435 (2004).

4. Konings, R. J. M., et al.: EU report 19928 (2001).

5. Ledergerber, G., Degueldre, C., Heimgartner, P., Pouchon, M. A., Kasemeyer, U.: Inert matrix fuel for the utilisation of plutonium. Prog. Nucl. Eng. 38, 301 (2001).

6. Sickafus, K. E., Matzke, H., Hartmann, H., Yasuda, K., Valdez, J. A., Chodak, III P., Nastasi, M., Verrall, R. A.: Radiation damage effects in zirconia. J. Nucl. Mater. 274, 66 (1999).

7. Gong, W. L., Lutze, W., Ewing, R. C.: Zirconia ceramics for excess weapons plutonium waste. J. Nucl. Mater. 277, 239 (2000).

8. Idemitsu, K., Arima, T., Inagaki, Y., Torikai, S., Pouchon, M. A.: Manufacturing of zirconia microspheres doped with erbia, yttria and ceria by internal gelation process as a part of a cermet fuel. J. Nucl. Mater. 319, 31 (2003).

9. Hellwig, C., Heimgartner, P., Tomita, Y., Kono, S.: Sphere-pac filling for irradiation tests of the FUJI project. Proceedings of the Global 2003 Conference, New Orleans, USA, November 16-20 (2003), pp. 1348-1353.

10. Suryanarayana, S., Kumar, N., Bamankar, Y. R., Vaidya, V. N., Sood, D. D.: Fabrication of $\mathrm{UO}_{2}$ pellets by gel pelletization technique without addition of carbon as pore former. J. Nucl. Mater. 230, 140 (1996).

11. Arima, T., Idemitsu, K., Yamahira, K., Torikai, S., Inagaki, Y.: Application of internal gelation to sol-gel synthesis of ceriadoped zirconia microspheres as nuclear fuel analogous materials. J. Alloys Compd. 394, 271 (2005).

12. Ledergerber, G., Ingold, F., Stratton, R. W., Alder, H. P., Prunier, C., Warin, D., Bauer, M.: Preparation of transuranium fuel and target materials for the transmutation of actinides by gel coconversion. Nucl. Technol. 114, 194 (1996).

13. Collins, J. L., Lloyd, M. H., Fellows, R. L.: The basic chemistry involved in the internal-gelation method of precipitating uranium as determined by $\mathrm{pH}$ measurements. Radiochim. Acta 42, 121 (1987)

14. Winston, C.: Analytical Chemistry by Open Learning: X-Ray Methods. Wiley, New York (1985), pp. 131-175.

15. Winterer, M.: Nanocrystalline Ceramics: Synthesis and Structure. Springer, Heidelberg (2002), pp. 21-23.

16. Nohman, A. K. H., Ismail, H. M.: Consequences of foreign salt additives on the structure and texture of some metal oxides. Coll. Surf. A 136, 237 (1998).

17. Gusev, E. A., Dalidovich, S. V., Krasovskaya, L. I.: Investigation of urotropine thermal decomposition reaction in self-generated atmosphere by means of thermal analysis method. Thermochim. Acta 93, 21 (1985).

18. Schaber, P. M., Colson, J., Higgins, S., Thielen, D., Anspach, B., Brauer, J.: Thermal decomposition (pyrolysis) of urea in an open reaction vessel. Thermochim. Acta 424, 131 (2004).

19. Aronne, A., Marotta, A., Pernice, P., Catauro, M.: Sol-gel processing and crystallization of yttria-doped zirconia. Thermochim. Acta 275, 75 (1996).

20. Suresh Kumar, K., Mathews, T., Bhat, N. P.: Study on thermal decomposition and sintering behaviour of internally gelated simulated inert matrix fuel. Thermochim. Acta 427, 27 (2005).

21. Suresh Kumar, K., Mathews, T.: Sol-gel synthesis and microwave assisted sintering of zirconia-ceria solid solution. J. Alloys Compd. 391, 177 (2005).

22. Barrier, D. C.: Characterisation and fabrication of zirconia and thoria based ceramics for nuclear applications. $\mathrm{PhD}$ thesis, Technische Universität Aachen (2005).

23. Matthews, R. B., Hart, P. E.: Nuclear fuel pellets fabricated from gel-derived microspheres. J. Nucl. Mater. 92, 207 (1980).

24. Bukaemskiy, A. A., Barrier, D., Modolo, G.: Physical properties of $8 \mathrm{~mol} \%$ ceria doped yttria-stabilised zirconia powder and ceramic and their behaviour during annealing and sintering. J. Eur. Ceram. Soc. 26, 1507 (2006). 